\title{
INCIPIENT MOTION RESPONSE DETECTION OF ARTICULATED COASTAL REVETMENT UNDER WAVE LOADING
}

\author{
Edmond J. Russo, Jr., Ph.D., P.E., ${ }^{1}$ Clinton S. Willson, Ph.D., P.E., ${ }^{2}$ \\ and Heather D. Smith, Ph.D. ${ }^{2}$
}

\begin{abstract}
Articulated coastal revetments (ACRs) are armoring options for abating earthen levee wave erosion. Stability criteria for ACR design typically allow initial, minor damage during design wave loading conditions (USACE, 2006). Minor wave damages may worsen progressively if not repaired before another design wave loading event. If minor ACR damages evolve under wave action to the point of unraveling, the underlying levee will become exposed to wave forces that could result in breaching (Pilarczyk, 1998). Vulnerability exists in this scenario for catastrophic flood risk management system failure. Current ACR stability limits for maintaining structural integrity under wave attack exist between the thresholds of structure incipient motion and that of initial damage criteria. Using an ACR stability limit that maintains structural integrity would greatly reduce the potential of repeat damage resulting in armor failure. A design challenge exists due to a knowledge gap in detecting and analyzing ACR performance between the thresholds of incipient motion and initial damage (Herbich, 1999). In this research, the threshold of incipient motion for ACRs is explored through small-scale experimentation. Data analysis, including correlations between hydrodynamic forcings and structure responses, extended our understanding of ACR system behavior in specific structural configurations and wave loading conditions.
\end{abstract}

Keywords: incipient motion; articulated coastal revetment; wave loading

\section{INTRODUCTION}

Pilarczyk (1998) explains that wave action impacts have the potential to result in soil erosion on the seaward faces and crown of exposed earthen dike (i.e., levee) structures. Figure 1 illustrates the effect of near shore seaward slope wave breaking and run up on a vegetated earthen levee in the vicinity of Eastern New Orleans, Louisiana, USA, which caused stripping of the vegetation layer and embankment soil loss during Hurricane Gustav in 2008 (USACE, 2008). Conventional erosion-abating armor may impose loadings that induce subsidence of earthen levees and underlying foundation soils, presenting a challenge in maintaining required design crown elevations of flood risk management systems. A new approach using continuously-connected, articulated coastal revetment (ACR) systems may have potential to resist wave attack while being significantly lighter than traditional designs.

Proper design for sloping revetments requires an understanding of the three modes of instability: uplift, sliding, and toe roll-up, which are summarized by McDonnell (1998), Pilarczyk (1998), and Herbich (1999). A field prototype-scale investigation was conducted in coastal Louisiana to assess the performance of ACRs in resisting a range of wave loading conditions (Russo, 2003). Previous work and this experiment demonstrated an increased need for understanding the processes leading to the incipient motion of ACR systems and translating this to the development of suitable design procedures. Design procedures should include:

- optimizing armor dimensions to resiliently resist specified wave loadings when ACR is considered the most appropriate application, and

- ensuring the ground pressures exerted by the armor layer are able to be lowered in comparison to alternative designs, for use in conditions where levee subsidence is a concern.

The work presented herein focuses on the investigation of ACR incipient motion through experimentation at laboratory scales. Small-scale physical modeling was conducted based on dimensional analysis and similitude criteria, using principles of hydrodynamics and structure mechanics of ACR system configurations at incipient motion, under short-crested, irregular wave conditions. The experimental system used high-resolution (both spatially and temporally) instrumentation to observe and record structure movement as an interconnected system of blocks on a seaward-facing slope under wave attack. Data analysis, including correlations between hydrodynamic forcings and structure responses, extended our understanding of ACR system behavior in specified structural configurations and wave loading conditions.

\footnotetext{
${ }^{1}$ Ecosystem Evaluation and Engineering Division, Environmental Laboratory, U.S. Army Engineer Research and Development Center (ERDC), 3909 Halls Ferry Road, Vicksburg, Mississippi, 39180, USA

${ }^{2}$ Department of Civil and Environmental Engineering, Louisiana State University, Baton Rouge, Louisiana, 70803, USA
} 


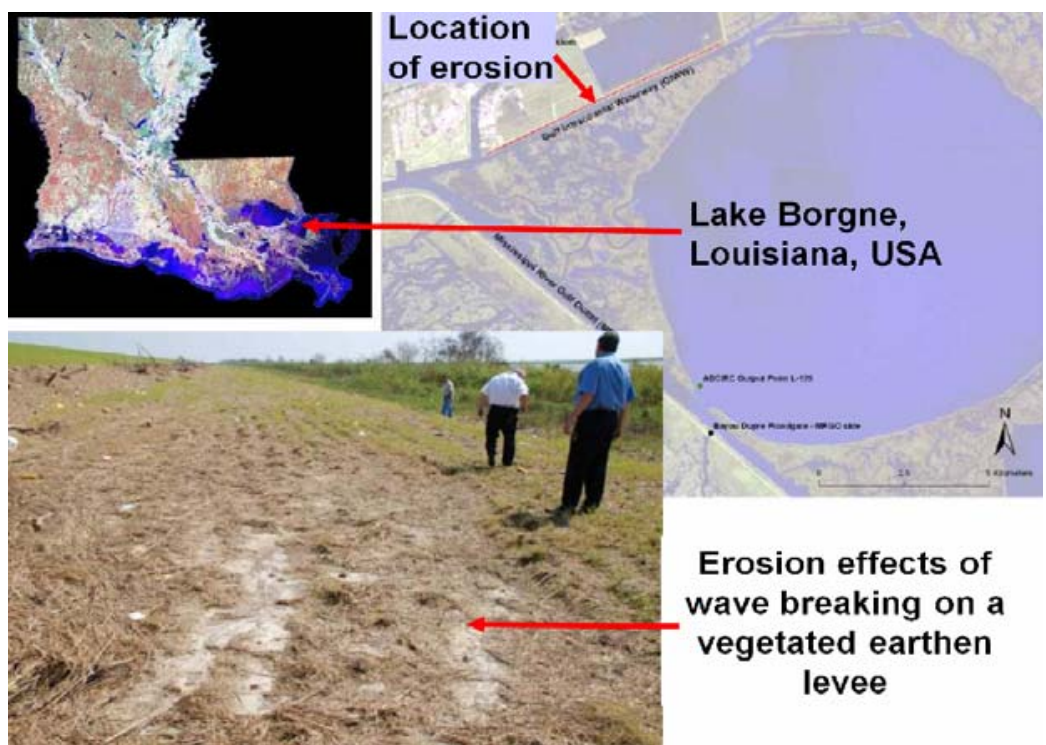

Figure 1. Erosion effects of near shore seaward slope wave breaking on a vegetated earthen levee, vicinity of Eastern New Orleans, Louisiana, USA (USACE, 2008).

\section{BACKGROUND}

Modeling an ACR system involves identifying modes of armor unit instability under design forces at the toe and on the slope. Anchoring of the ACR at its head and toe enables limiting its motion to vertical displacement on the slope. Filter stone and geotextile fabric underlying the armor layer act as supporting elements for design stability. These features must:

- maintain separation between the armor and bank soils,

- manage hydrodynamic forces under the revetments during wave attack, and

- retain bank soils from erosion through the filter layer and armor blocks (McConnell, 1998).

Consideration must be given to geotechnical slope stability, bearing capacity, and settlement of the levee and its underlying foundation soils, for structural support and to facilitate the construction process (Terzaghi, Peck, and Mesri, 1996). System design integrity must be ensured during construction to achieve expected design performance.

USACE (1989) model tested Articulated Concrete Mattresses (ACMs) as an ACR system for earthen dike protection at Lake Okeechobee, Florida. Extensive theoretical, computational and experimental research has been performed in the Netherlands on ACR systems (Pilarczyk, 1998). Prior testing involved identification of modes of structure instability under regular and irregular wave action, leading to mathematical model formulation. These works were aimed at establishing limiting wave heights for stability of ACR design configurations, offering options that effectively decrease armor unit size for comparable designs of individually-placed armor units.

Traditional practice for evaluating structure stability under specified wave loading conditions is based on "no damage" criteria to the structure (ASCE, 2003). As a practical matter, "no damage" involves a threshold limit of very minimal damage rates, which are considered repairable during routine maintenance (USACE, 2006). However, this approach could be a concern in flood risk management if structure maintenance is not able to be performed between damaging coastal storm events, as is generally assumed possible by traditionally-observed practices.

Theoretical equilibrium exists when destabilizing wave loading forces are in balance with restoring gravitational forces of the structure. Tests of prior works summarized by Herbich (1999), which were conducted through traditional methods that involve structure displacement and/or damage under wave loadings, were generally able to measure structure performance between 3.7 and 8 of the ratio of destabilizing-to-restoring forces. For observations that were near a value of 3.7, the ACR experienced onset of damage (e.g., armor unit permanent dislocation or breakage). For values near 8, structures experienced catastrophic unraveling. Despite being the best available physical data measurable to-date, Herbich (1999) characterized structure performance for design as being highly uncertain in this range of response under specified wave forcings. Additionally, there is no explicit, 
quantitative correspondence in ACR performance under wave loadings between the USACE (2006) "no damage" criteria and the summary of tests by Herbich (1999) on the ratio of destabilizing-torestoring forces. Given the motivation of this manuscript that irregular ACR maintenance has the potential to introduce system performance vulnerabilities, our research explored a new lower limit near the threshold of equilibrium that preserves the design integrity of the ACR structure under specific wave loadings.

\section{PHYSICAL MODELING}

A physical model at 1:25 model-to-prototype scale was subjected to short crested irregular wave loadings to detect vertical incipient ACR structural motions. Figures 2(a) and 2(b) illustrate the laboratory physical model wave flume setup (Hughes, 2008) and modeled ACR design after Russo (2003), respectively. This work was performed in the J.V. Hall Physical Modeling Facility at ERDC, using a flume that has dimensions of $45 \mathrm{~m}$ long, $0.91 \mathrm{~m}$ wide, and $0.91 \mathrm{~m}$ deep. The bottom geometry of the flume including the transition from deep to shallow water, as well as the levee structure shape, were held constant during testing. Armor block thicknesses of 76.2-, 152-, and 229-mm were tested in combinations with 152-, 229-, and 305-mm thick pervious filter layers (all dimensions in prototype scale), anchored at the ACR head and toe over the filter layer, and constructed on an impervious levee slope. The ACR head and toe were fixed, consistent with typical field design approaches, enabling focus on incipient motions occurring on the slope. The ACR and filter layers at model scale had
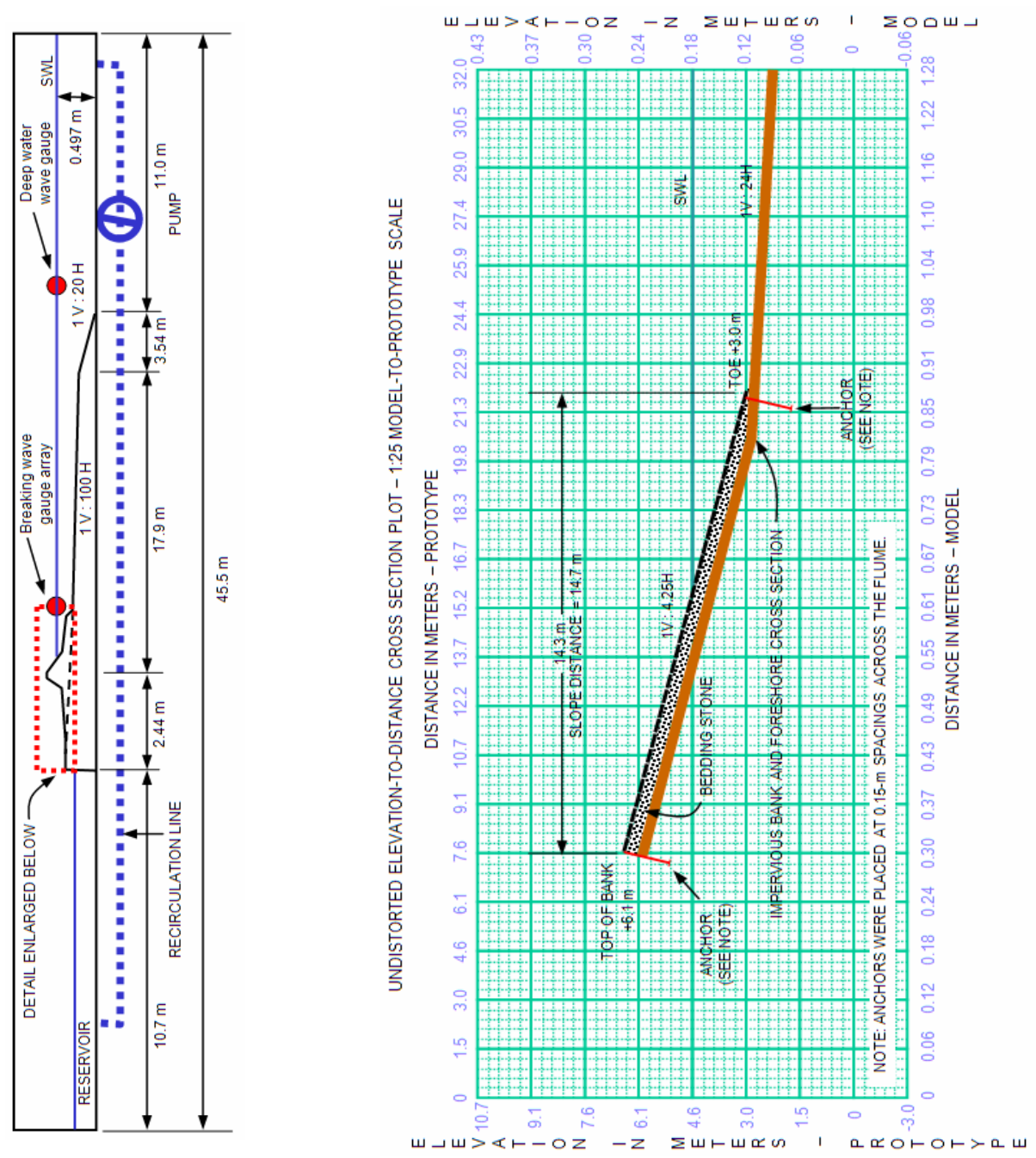

Figure 2(a) (Above, left). Elevation view of laboratory physical model wave flume (Hughes, 2008). Figure 2(b) (Above, right). Elevation view of modeled ACR prototype design (Russo, 2003). 
porosities allowing internal turbulent transmission during wave impact. Thus, the scale model simultaneously obeyed Froude and Reynolds criteria for achieving prototype similarity for flow conditions imposed.

Figure 3 displays the instrumented physical model setup in the flume. Gauges were positioned in the flume to measure water surface elevation changes at $50 \mathrm{~Hz}$ for the deep water waves, breaking waves, slope runup and backwash waves. Water level changes and vertical ACR displacements were observed at ten, equally spaced $(1270 \mathrm{~mm}$, prototype scale) stations along the ACR slope. Station numbering began at the structure toe and ascended up-slope. The still water level (SWL) was positioned at Station (STA) 5 for all testing. STAs 3 and 4 resided just below the SWL, which is where frequent ACR uplift occurred under wave action. Slope runup gauges were positioned at STAs 3, 5, and 7. Linear interpolation was used to compute wave runup signals for select locations between gauge points along the slope. Piezometers were ported into the bottom of the ACR filter layer at the midpoint between each station on the ACR structure slope to collect pressure data in the filter layer under wave action. Side-mounted high definition video was taken at $100 \mathrm{~Hz}$ on the structure slope to record vertical displacements of the ACR during wave attack.

Short crested, irregular wave loadings were imposed on the model structure during testing. Significant wave heights for testing were set at between 305 to $1524 \mathrm{~mm}$ in height, in $305 \mathrm{~mm}$ increments, with select combinations of 3, 6, and 9 sec periods (prototype scale). Test combinations of wave height and period were established based on the minimum-observed wave energy required to induce incipient motion of ACR structure configurations. During testing, wave runup water did not overtop the sloping structure. Wave runup and backwash permeated the porous revetment armor layer and entered into the underlying porous filter media lying on the impervious base. The impervious base prevented water from infiltrating into the model structure slope to emulate the case of a highlyimpermeable levee where effective amounts of wave water do not enter the earthen structure under short event duration wave loadings.

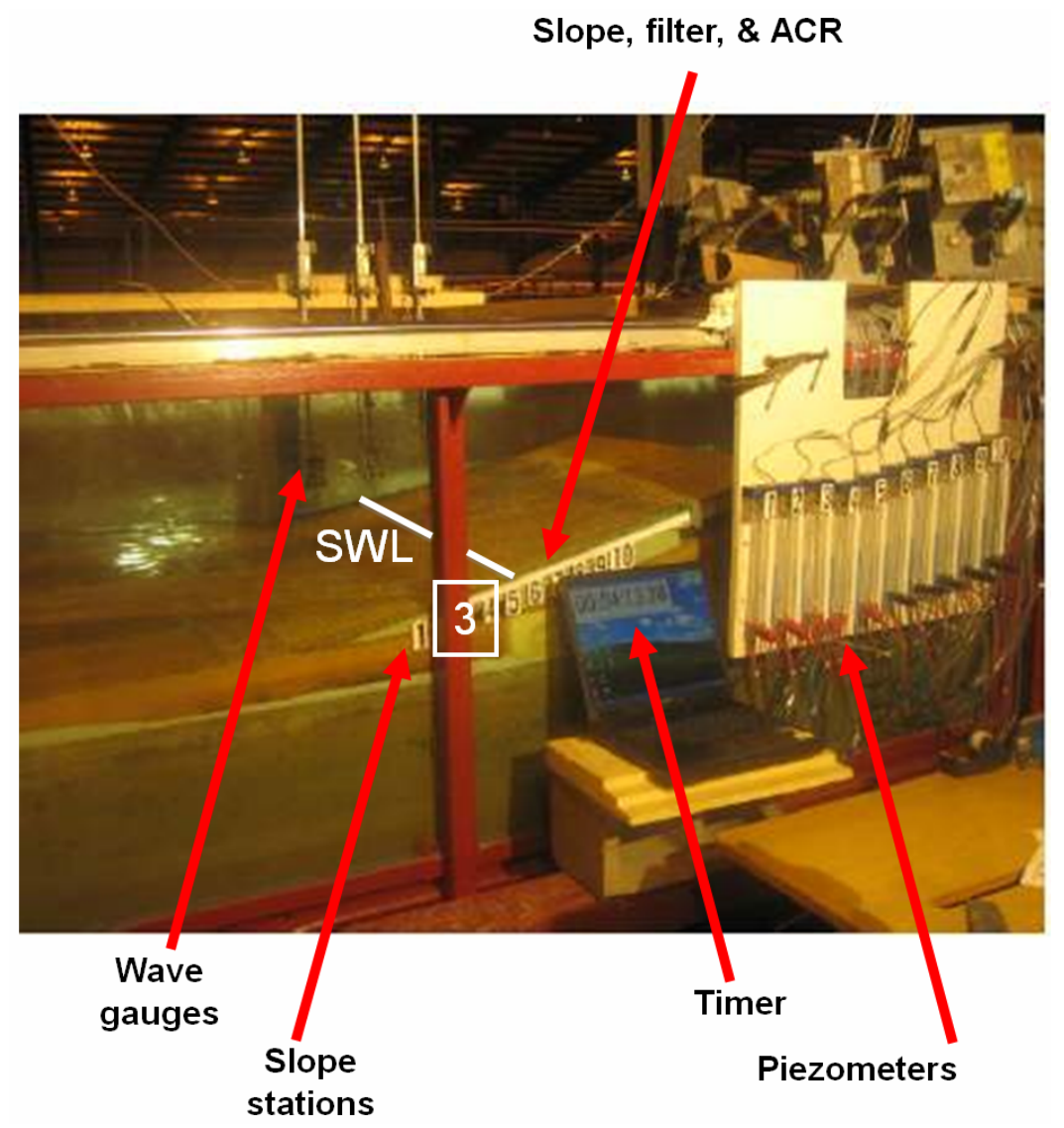

Figure 3. Instrumented physical model setup in flume. 


\section{RESULTS}

In the following, we present results from one ACR test configuration under a wave height and period combination that was minimally able to induce incipient motion of the ACR. The deep water wave conditions generated in the flume were $610 \mathrm{~mm}$ significant wave height, 6 sec period. The ACR configuration comprised of 76.2-mm (3-inch) thick block (“A3”) and 229-mm (9-inch) thick filter layer ("F9"), with waves and structure dimensions described at prototype scale. Figure 4 illustrates a typical deep water wave signal generated in the flume during testing, representing a $610 \mathrm{~mm}$ significant wave height, 6 sec period (prototype scale dimensions); or $24 \mathrm{~mm}$ significant wave height, 1.2 sec period (model scale dimensions). Figure 5 presents wave runup measured at STA 3 of ACR configuration A3F9. Figure 6 depicts the piezometric head signal at STA 3 for this test configuration.

The waves acting on the ACR structure for each test had statistically stationary parameters after initial energy build-up in the tank. The wave properties underwent transformation during breaking and runup, with successive waves inducing transient, short-duration standing water level fluctuations on the slope with respect to the SWL (Figure 5). While some water entered the revetment filter media through the armor layer in wave runup and backwash, wave discharge also moved over the top of the armor layer during these processes, exhibiting flow seperation. A fluctuating piezometric head rapidly occurred in the filter layer beginning with the onset of wave attack. The phreatic surface in the filter layer built and fell from just below the SWL up to near the elevation of the maximum wave runup. Time lags and water level damping occurred between the runup and piezometric head signals during testing.

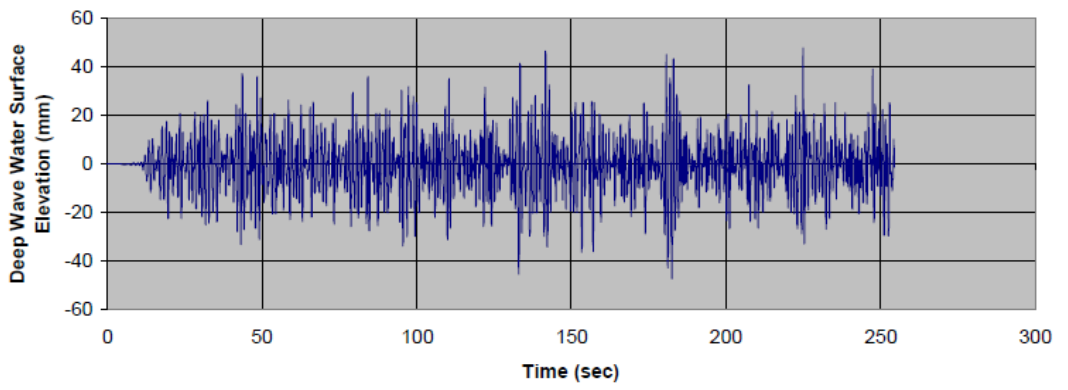

Figure 4. Deep water wave signal, model scale dimensions.

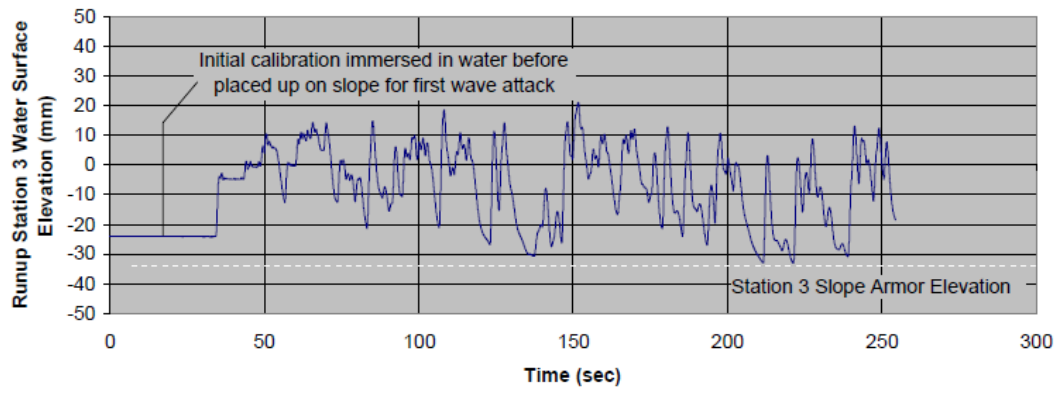

Figure 5. Runup wave gauge signal at slope STA 3, model scale dimensions.

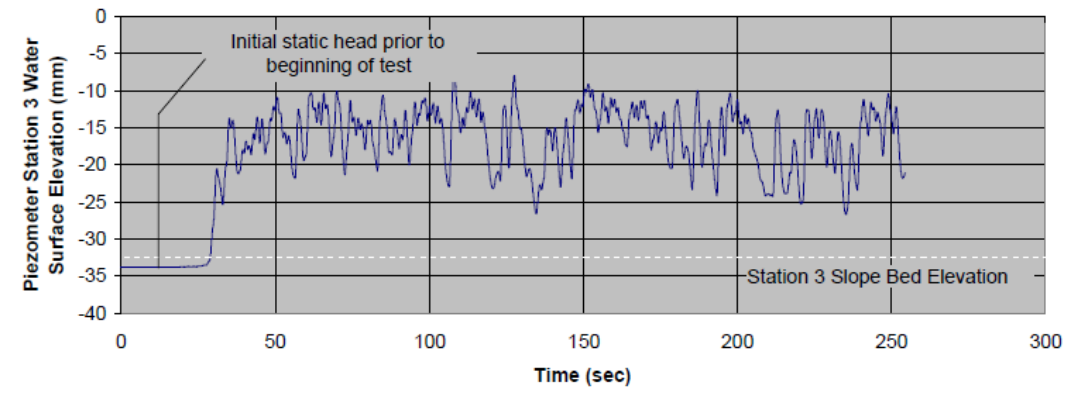

Figure 6. Piezometer gauge signal at slope STA 3, model scale dimensions. 
Figure 7 presents still frames from video of the laboratory wave flume experimentation, with sequential actions occurring from panels (a) to (c) and (d) to (f) for surging and collapsing waves, respectively. Surging wave conditions during breaking were defined as those where there was a decreasing water surface gradient trailing the leading edge of the runup. Collapsing wave conditions were considered as those where the trailing wave water surface was higher than the runup at the leading edge. These definitions were applied during time series analysis of the test data streams, which is described in that to follow. The panels to the left and right of Figure 7 respectively illustrate surging and collapsing time series of ACR structure movements under wave attack. In these time lapse progressions, the waves build, break, and dissipate in runup on the slope. Typically, the collapsing waves induced greater uplift than observed during surging wave conditions, as shown in Figure 7.

The ACR displacements (Figure 8) consisted of buoyant weight uplift and rotation, exhibiting intermittent behavior under the irregular wave cycles. Minimal permanent ACR displacement and no damage were allowed during testing. Commensurate to the time series images of Figure 7, Figure 9 illustrates a detailed view between STAs 3-4 during one surging runup wave (upper panel) and the associated ACR movements (lower panel). Here, a characteristic height-to-length change is visible with ACR ripple propagation upslope. Likewise, Figure 10 shows one collapsing runup wave (upper panel) and the associated ACR vertical displacements (lower panel) during that time. The resolution of the ACR vertical displacement signal was limited to $1 \mathrm{~mm}$ geometrically, and by $0.02 \mathrm{sec}$, temporally, which leads to the step-wise nature of the plots in Figures 9 and 10.

For the purpose of performing time-averaged wave-by-wave data analysis, wave breaking celerity for the specific conditions of the test was estimated according to Svendsen, et al (2003) under the operating assumptions described by Bonneton (2004). Figure 11 presents a plot of the height (H)-tolength (L) ratios of ACR vertical displacements propagating on the structure slope mid-way between STAs 3-4, for the corresponding water level changes on the slope, expressed as runup wave height $(\mathrm{H})-$ to-half length (L/2) below STA 3-4. The values of the surging and collapsing runup wave water level changes on the slope are distinguished in this data plot. From these results, under a specific set of test conditions, the possible maximum envelope of ACR vertical displacement potential under wave attack is delineated for both surging and collapsing runup wave conditions. For an ACR non-dimensional height-to-length vertical displacement of 0.01 , Figure 12 presents the cumulative distribution function of corresponding wave runup water level changes, expressed as $\mathrm{H} /(\mathrm{L} / 2)$.

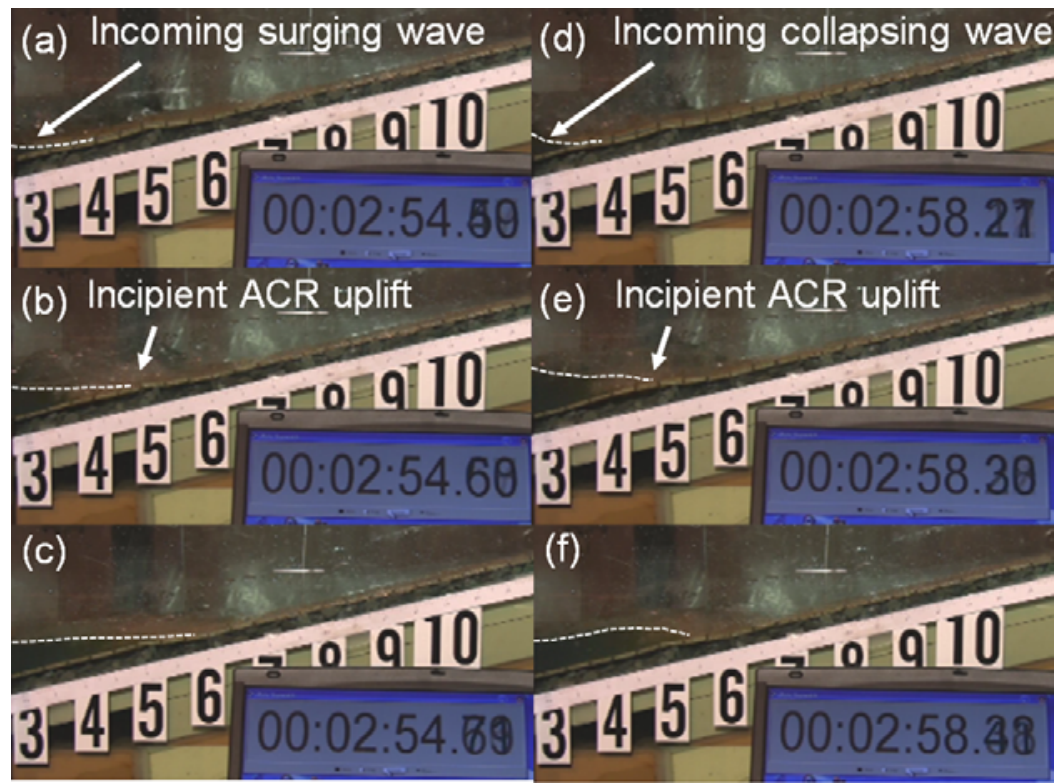

Figure 7. ACR structural response under wave loadings for configuration A3F9. A surging wave approaches from the left (panel (a)), impacts the structure, inducing ACR motion (panel (b)), and runs up the ACR with continued mat displacement (panel (c)). Similarly, a collapsing wave approaches from the left (panel (d)), impacts the structure, inducing ACR motion (panel (e)), and runs up the ACR with continued mat displacement (panel (f)). 


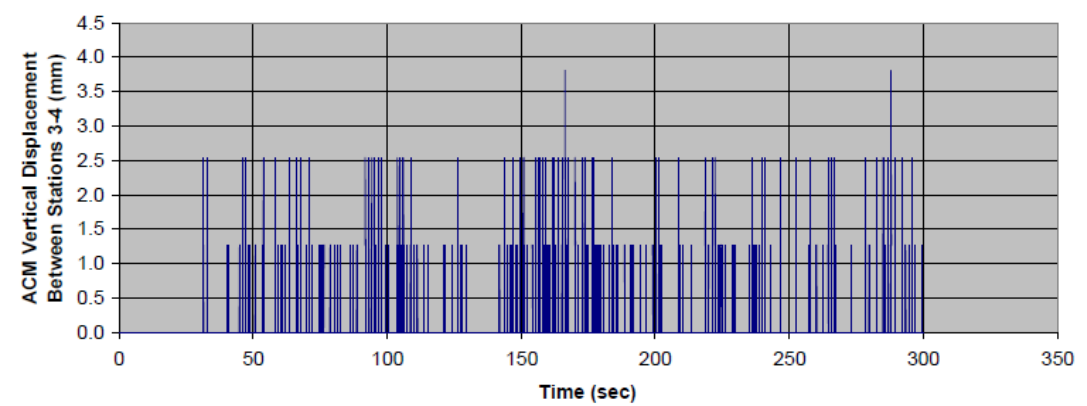

Figure 8. ACR displacement signal between slope STAs 3-4 for configuration A3F9, model scale dimensions.
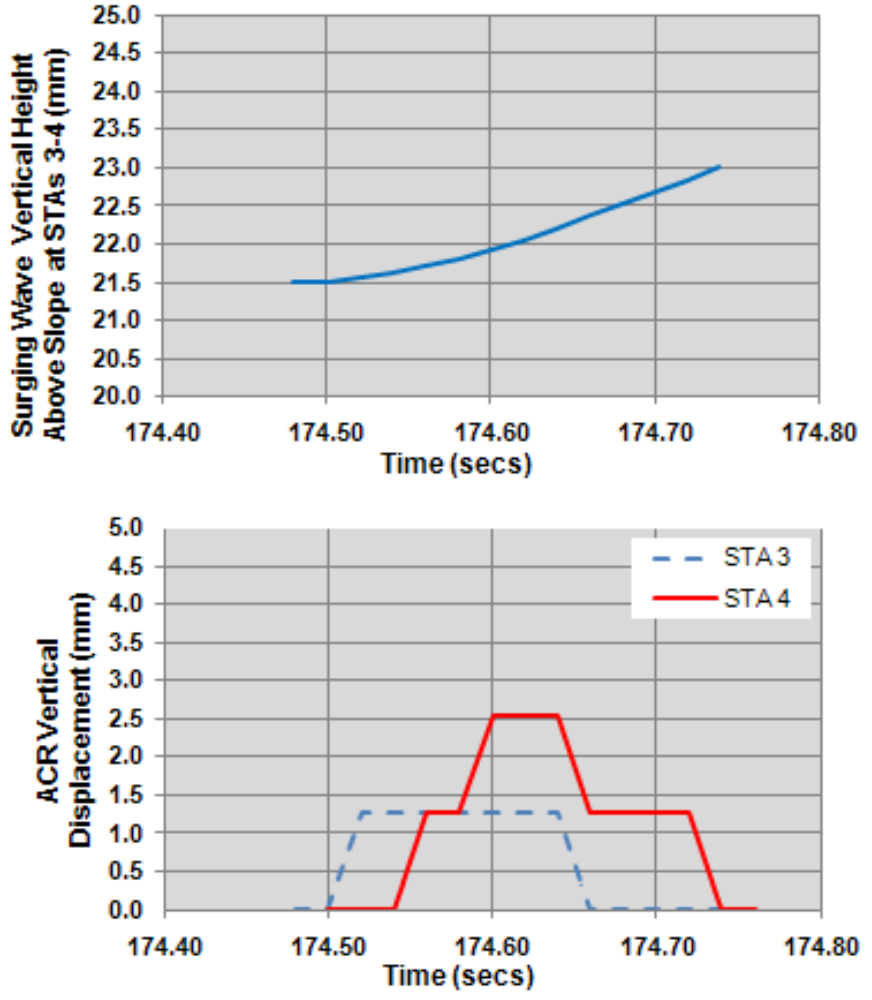

Figure 9. ACR displacement signal during surging wave runup at slope STAs 3-4 for configuration A3F9, model scale dimensions.

\section{DISCUSSION}

The velocity field caused by turbulence during wave breaking built, and then decayed on the structure slope, as the leading edge of wave runup ascended. The ACR structure experienced inertial and drag forces due to passage of the wave on the slope. Movement of the ACR is resisted by gravitational force, as well as by explicit system interlock due to articulation between blocks. Turbulent motions in the runup wave caused sufficient forces to induce incipient motion of the ACR structure near the SWL.

The typical structure response observed during surging and collapsing wave runup conditions was a propagating ACR ripple up-slope, exhibiting a characteristically changing height and length. The ACR ripple developed a relatively high height-to-length ratio with initial wave attack, and then decayed with wave energy dissipation. Based on the data shown in Figure 11, collapsing waves generally induced relatively greater vertical displacements of the ACR at STA 3-4 during testing than under surging wave conditions. The specific example shown in Figure 12, for an ACR nondimensional height-to-length vertical displacement of 0.01 , shows the potential for informing ACR design decisions based on risk tolerance for specific wave loading conditions. 

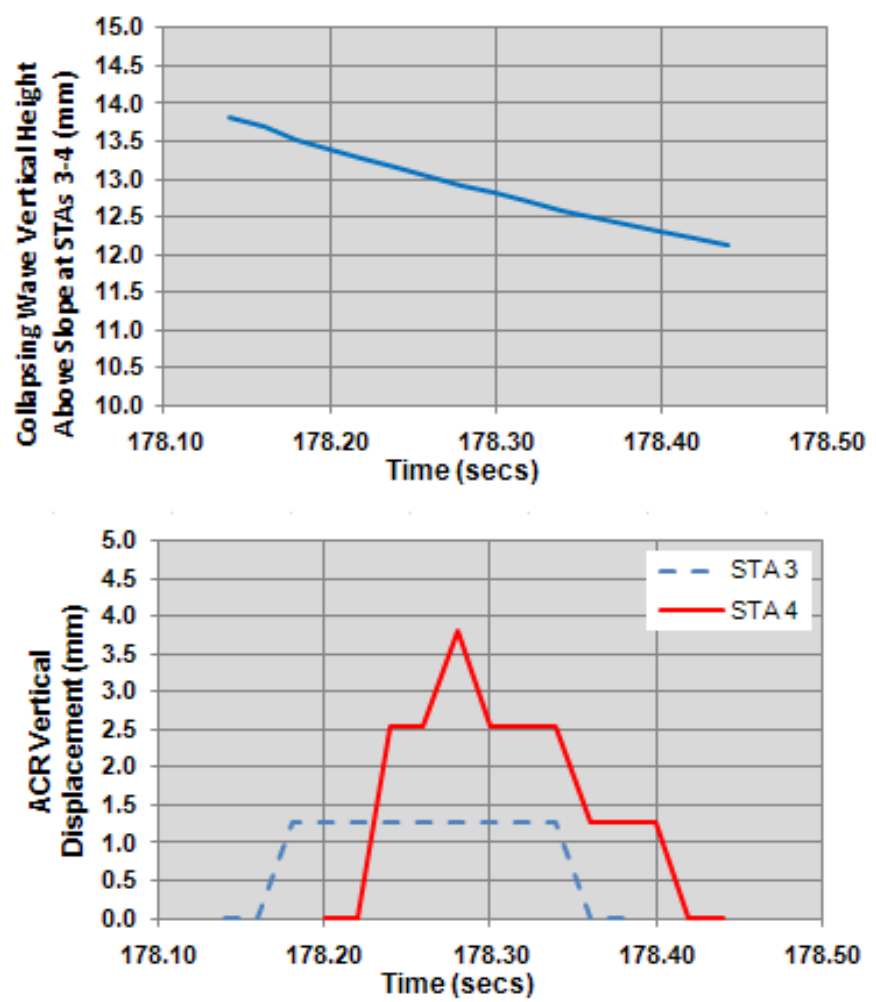

Figure 10. ACR displacement signal during collapsing wave runup at slope STAs 3-4 for configuration A3F9, model scale dimensions.

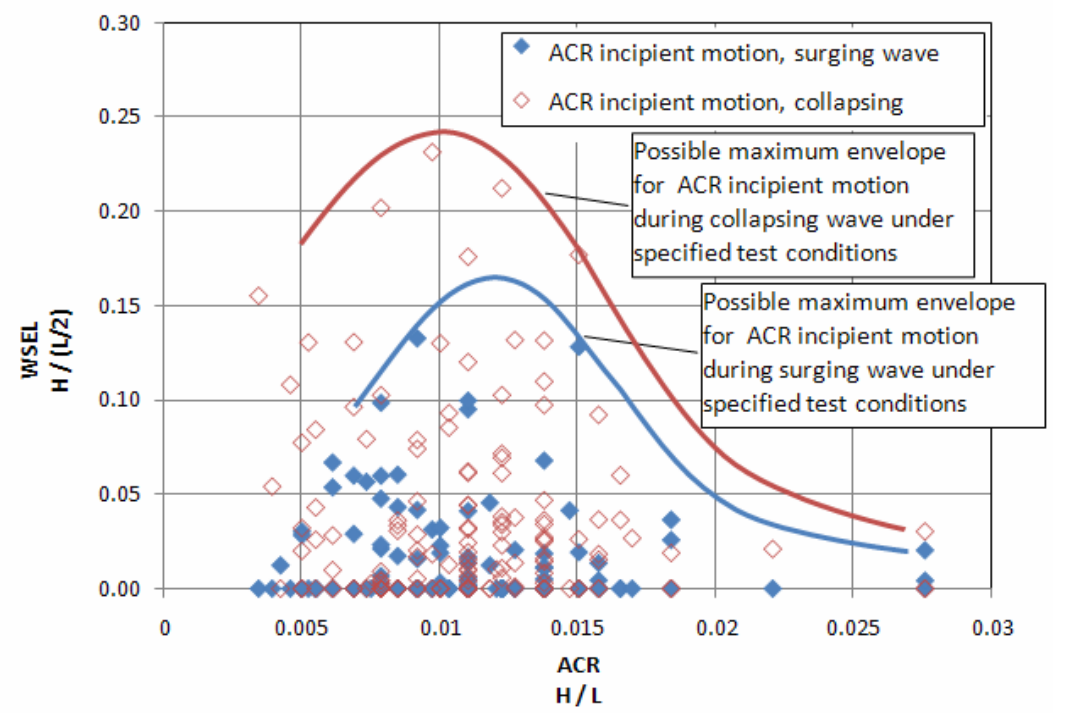

Figure 11. Non-dimensional ACR displacements corresponding to dimensionless water surface elevation (WSEL) changes on the slope at STAs 3-4.

Observations during testing supported conceptualization of a time-varying cyclic process, as shown in Figure 13, consisting of: (1) wave run up impact, (2) ACR element displacement, (3) new element position, and (4) changed system hydrodynamics. Given the irregular wave loading conditions, individual wave heights and lengths varied within expected ranges during each test. Using the dynamic conceptualization shown in Figure 13, longer waves were of sufficient duration so that the water had time to penetrate and dissipate into the ACR structure, resulting in relatively low armor uplift force. In contrast, the time for penetration and dissipation for shorter waves was less than for longer waves and resulted in relatively greater uplift force. 


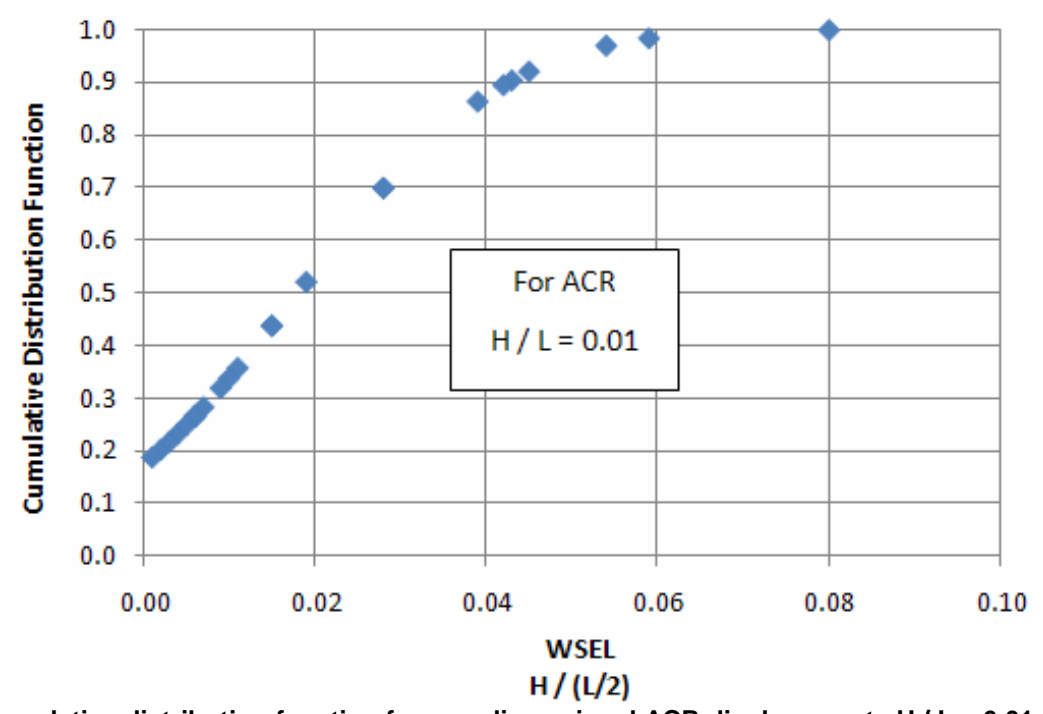

Figure 12. Cumulative distribution function for non-dimensional ACR displacements $H / L=0.01$ corresponding to non-dimensional water surface elevation changes on the slope at STAs 3-4.

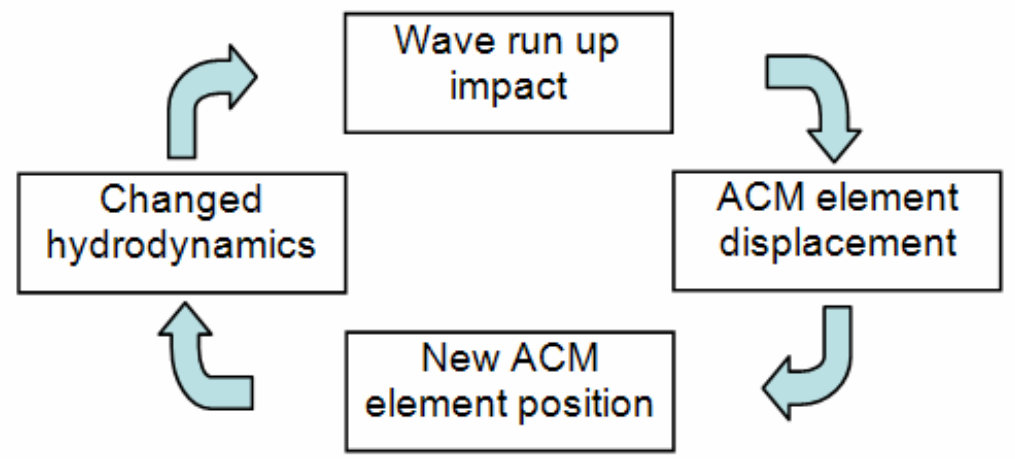

Figure 13. Cyclic wave impact - ACR response process.

Combining the guidance from Pilarczyk (1998) with observations via field prototype ACR testing (Russo, 2003) and the laboratory physical model flume testing described herein, we are able to list the variables believed important in modeling uplift motions of ACR overlaying an aggregate filter layer with impervious sloping base:

- Armor mass, expressed in terms of armor layer thickness and material density relative to the density of wave water,

- Armor geometry and surface roughness,

- Armor system connectivity, i.e., articulation,

- Armor layer wave water flow conveyance capacity, defined as porosity,

- Filter layer flow conveyance capacity, described as porosity,

- Structure slope geometry fronting wave attack,

- SWL with respect to structure slope and its crown elevation,

- Wave height, period, and direction with respect to the structure, and

- Construction quality and post-construction structure maintenance conditions with respect to design specifications.

\section{CONCLUSIONS}

Results from this small scale physical modeling study demonstrated a new method for extending the measurement and analysis of ACR performance near the threshold of incipient motion under irregular wave attack. During testing, wave propagation, breaking, runup, and backwash on sloping ACR configurations with shallow foreshores exhibited complex interactions with wave water 
movement through the porous ACR and filter bedding laid on an impervious slope. Flow separation occurred during runup on the structure followed by flow into the filter layer. Wave water returned both down the top surface of the ACR and through the filter media. The weight of the ACR structure and the system articulation provided resistance to the buoyant uplifting and inertia- and drag-related rotation forces of the runup waves. The most frequent ACR movements occurred near the SWL. The ACR structure exhibited characteristic vertical displacement ripples upslope under cycles of wave loading. Possible maximum envelopes of ACR incipient motion for surging and collapsing wave runup impacts were discovered under specific test conditions. The collapsing wave condition appears to have a relatively greater influence on ACR movements than for surging waves. Expanded test results using this method in the future, for combinations of varying wave loading and structure configurations, have potential to inform design decisions for probabilistically reducing the potential of repeat damage resulting in armor failure. Finally, a dynamic physical process of wave-structure interaction was conceptualized based on the flume investigations, which has potential to scientifically support future mathematical model formulation research.

\section{REFERENCES}

ASCE. 2003. Advances in coastal structure design. Ocean Engineering Committee, Rubble Mound and Breakwater Committee, and Coastal Practice Committee of Coasts, Oceans, Ports, and Rivers Institute of ASCE, Reston, Virginia, 220 pp.

Bonneton, P. 2004. Wave celerity in the inner surf zone. Proceedings, 29th International Conference on Coastal Engineering. 1, 392-401.

Herbich, J. 1999. Handbook of coastal engineering. McGraw-Hill, New York, New York, 1152 pp.

Hughes, S.A. 2008. Combined wave and surge overtopping of levees: flow hydrodynamics and articulated concrete mat stability. ERDC/CHL TR-08-10, ERDC, Vicksburg, Mississippi.

McConnell, K. 1998. Revetment systems against wave attack - A design manual. Thomas Telford Publishing, London, England, 162 pp.

Pilarczyk, K.W. 1998. Dikes and revetments: Design, maintenance, and safety assessment. Balkema Publishing, Rotterdam, Netherlands.

Russo, E.J. 2003. Evaluation of bank line revetment alternatives to abate ship wake erosion. Independent Study, Department of Civil and Environmental Engineering, Tulane University, New Orleans, Louisiana.

Svendsen, I., Qin, W., and Ebersole, B. 2003. Modeling waves and currents at the LSTF and other laboratory facilities. Coastal Engineering. 50, 19-45.

Terzaghi, K., Peck, R., and Mesri, G. 1996. Soil mechanics in engineering practice. $3^{\text {rd }}$ Edition, John Wiley and Sons, Inc., New York, New York, 549 pp.

USACE. 1989. Stability of articulated concrete mattresses for Herbert Hoover dike improvements, Lake Okeechobee, FL. Technical Report CERC-89-12, Waterways Experiment Station, Coastal Engineering Research Center, Vicksburg, Mississippi.

USACE. 2006. Coastal Engineering Manual. USACE, Washington, D.C.

USACE. 2008. Photograph of earthen levee slope vegetation and embankment soil loss, Lake Pontchartrain and Vicinity HSDRRS, Louisiana. USACE, New Orleans District, New Orleans, Louisiana. 